\title{
Milk Urea Nitrogen Concentration: Heritability and Genetic Correlations with Reproductive Performance and Disease
}

\author{
R. G. Mitchell, ${ }^{1}$ G. W. Rogers, ${ }^{1}$ C. D. Dechow,${ }^{2}$ J. E. Vallimont ${ }^{2}$ J. B. Cooper, ${ }^{1}$ \\ U. Sander-Nielsen, ${ }^{3}$ and J. S. Clay ${ }^{4}$ \\ ${ }_{1}^{1}$ Department of Animal Science, University of Tennessee, Knoxville 37996 \\ 2Department of Dairy and Animal Science, The Pennsylvania State University, University Park 16802 \\ ${ }^{3}$ Danish Agricultural Advisory Center, Aarhus, Denmark 8200 \\ ${ }^{4}$ Dairy Record Management Systems, Raleigh, NC 27603
}

\begin{abstract}
The objectives of this study were to estimate the heritability of milk urea nitrogen (MUN) concentration and describe the genetic relationship between MUN and reproductive performance and between MUN and diseases in Holsteins. Dairy Records Management Systems (Raleigh, NC) provided lactation data. The Danish Agricultural Advisory Center provided breeding value estimates for diseases. Infrared (IR) and wet chemistry (WC) data were analyzed separately. Heritabilities and genetic correlations for 2 different measures of MUN and reproductive performance were estimated with an animal model using ASREML. Heritabilities for MUN were estimated using all lactations combined (lactations 1 through 5) and separately for first lactation and second lactation. Genetic correlations with reproduction and health were estimated separately for parities 1 and 2. Herd-test-day or herd-year-season along with age at calving and days in milk were included as fixed effects in all models. Heritability estimates for all lactations combined were 0.15 for WC MUN and 0.22 for IR MUN. Genetic correlations between WC MUN and 2 measures of reproductive performance, days to first service, and first service conception were not different from zero. In contrast, the genetic correlation between WC MUN and days open of 0.21 in first lactation and 0.41 in second lactation indicated that higher WC MUN values were associated with increased days open. Correlations among estimated breeding values for MUN and estimated breeding values for Danish diseases identified no significant relationships. Although the results of this study indicate that heritable variation for MUN exists, the inability to identify significant genetic relationships with several measures of disease or reproductive perfor-
\end{abstract}

Received September 22, 2004

Accepted August 23, 2005.

Corresponding author: G. W. Rogers; e-mail: grogers2@tennessee. edu. mance appears to limit the value of MUN in selection for disease resistance and improved reproduction.

(Key words: milk urea nitrogen, reproductive performance, disease, genetic correlation)

Abbreviation key: DO = days open, $\mathbf{I R}=$ infrared, $\mathbf{W C}=$ wet chemistry.

\section{INTRODUCTION}

Traditional selection programs used by dairy cattle breeders have been extremely successful in improving yield traits (USDA Animal Improvement Programs Laboratory, 2003). An undesirable correlated response to this selection strategy has been a decline in overall cow health and reproductive performance (Van Dorp et al., 1998; Rogers et al., 1999). This has resulted in increased efforts to develop selection criteria to improve cow health and reproductive performance.

Although evidence exists for considerable genetic variation in fertility measures (Pryce et al., 2001; Veerkamp et al., 2001; Berry et al., 2003) and disease resistance (Lin et al., 1989; Simianer et al., 1991; Van Dorp et al., 1998), heritability estimates for these traits are generally low. Daughter pregnancy rate, which is calculated from days open (DO) data, has an estimated heritability of 0.04 (VanRaden et al., 2004). Currently, no uniform method for collection of health data exists in the United States. Denmark employs a mandatory, centralized recording system for all health traits and publishes national genetic evaluations for numerous health and reproductive traits. Published heritability estimates for all health and reproductive traits are 0.05 or less (Danish Cattle Federation, 2003).

Milk urea nitrogen is considered a normal nonprotein nitrogen component in milk. Urea concentration in milk results as a by-product of protein metabolism (Moore and Varga, 1996). Digestion of dietary protein results in the production of ammonia. Ammonia is converted to urea primarily in the liver (Ferguson, 2003). Urea is then excreted from the body primarily through urine, but is also found in blood and milk (Moore and Varga, 
1996). Milk urea nitrogen levels have been used to evaluate herd nutritional status, as well as assess nitrogen excretion to the environment (Jonker et al., 1998).

Many DHI programs routinely offer MUN analysis to participating herds. Elevated MUN concentrations have been documented to adversely affect fertility (Melendez et al., 2000; Rajala-Schultz et al., 2001; Vallimont et al., 2003; Guo et al., 2004). Evidence of a phenotypic relationship between MUN concentrations and reproductive performance suggest the possibility that genetic evaluations for MUN could be useful in selection programs to improve reproductive performance and cow health.

The objectives of this study were 3-fold. The first objective was to estimate the heritability of MUN concentration. The second objective was to describe the genetic and phenotypic relationships between MUN and reproductive performance. Finally, the third objective was to estimate correlations among EBV for MUN generated from US lactation records and EBV for diseases from Denmark.

\section{MATERIALS AND METHODS}

\section{MUN Data}

Lactation records including MUN data obtained from Dairy Records Management Systems in Raleigh, North Carolina, were used in this study. Milk urea nitrogen concentrations were measured by either infrared (IR) or wet chemistry (WC) methods on test-day samples routinely collected through the DHI system. Infrared measures of MUN are indirect measures of MUN. Infrared MUN values are calculated from prediction equations that use spectrum analyses. Wet chemistry methods directly measure urea nitrogen in milk samples.

The initial data set included 625,000 lactations with 1 or more test-day MUN before July 2001. Records were edited to include only Holstein cows with valid identification from herds with more than 10 cows per testday and greater than $75 \%$ of the cows within the herd having valid MUN data for each test-day. Further edits eliminated records with missing or illogical birth or calving dates, DIM greater than 305, parities greater than 5 , and MUN values greater than $40 \mathrm{mg} / \mathrm{dL}$. Preliminary analyses indicated that MUN values greater than $40 \mathrm{mg} / \mathrm{dL}$ were indicative of improper milk sampling. A minimum of 5 contemporaries was required, with contemporaries for heritability analysis defined as cows of the same parity that had MUN recorded for the same herd-test-day. Data were excluded unless 5 contemporaries were available, even for parities 3 to 5 when they were analyzed. Cows entering a herd in midlactation and records with indications of abnormal samples were eliminated. Records with test-days before October 1998 were eliminated to ensure uniform calibration standards across all DHIA milk testing laboratories. Therefore, data were from test-days between October 1998 and March 2001. First-lactation records were edited to include cows that calved after 20 mo of age and before 36 mo of age. Second-lactation records were edited to include cows that calved after 30 mo of age and before 60 mo of age. Numbers of records and cows used to estimate heritabilities from the various data sets are in Table 1. An additional data set including records from cows with a minimum of 4 MUN observations per lactation was created to compare with Wood et al. (2003) who imposed this same edit on their data.

\section{Reproductive Performance Data}

Cows used to estimate heritabilities for MUN were also used to estimate correlations between MUN and reproductive performance. However, many cows with MUN had little information on reproductive performance. Additionally, only $25 \%$ of first-lactation cows with MUN and reproductive data had both MUN and reproductive data in second lactation. Several edits for reproductive information were applied to records on cows with MUN data. This reduced the number of records available to estimate correlations between MUN and reproductive performance. Each cow used in the analyses of the 3 reproductive traits (DO, first-service conception rate, days to first service) was required to have a MUN value within $\pm 30 \mathrm{~d}$ of first service and a verified reproductive status for a lactation as reported to DHIA (producer-designated code for open or pregnant determined by palpation). Days open was not calculated for first-lactation cows having a subsequent lactation but missing a first-lactation reproductive status code due to the possible bias of excluding some of the poorest first-lactation reproductive records that were missing a calving date in addition to missing a reproductive status code. The analysis of DO may have also been affected by our decision to use MUN within \pm 30 $d$ of first service because DO was not just a result of the first service. Use of MUN during periods late in lactation along with DO might produce results that are difficult to interpret as well. Edits were made to exclude records with days to first service $<25$ or $>200$ and DO $<25$ or $>365$. Due to limited observations of IR MUN and reproductive performance measures, correlations among IR MUN and reproductive measures were not calculated. Only the WC MUN data were used to estimate correlations between MUN and reproductive performance measures. The number of cows used to estimate the parameters for reproductive performance measures are in Table 2. 
Table 1. Number of MUN test-day records, number of cows in various data sets, means, standard deviations, heritability estimates, and repeatability estimates (SE) for MUN.

\begin{tabular}{|c|c|c|c|c|c|c|}
\hline & \multicolumn{3}{|c|}{ Infrared } & \multicolumn{3}{|c|}{ Wet chemistry } \\
\hline & $\begin{array}{l}\text { First } \\
\text { lactation }\end{array}$ & $\begin{array}{l}\text { Second } \\
\text { lactation }\end{array}$ & $\begin{array}{l}\text { Lactations } \\
1 \text { to } 5\end{array}$ & $\begin{array}{l}\text { First } \\
\text { lactation }\end{array}$ & $\begin{array}{l}\text { Second } \\
\text { lactation }\end{array}$ & $\begin{array}{l}\text { Lactations } \\
1 \text { to } 5\end{array}$ \\
\hline No. of records & 38,355 & 25,519 & 83,058 & 78,144 & 55,476 & 174,259 \\
\hline No. of cows & 13,950 & 9544 & 26,540 & 25,902 & 18,671 & 46,951 \\
\hline Mean & 12.62 & 13.21 & 12.92 & 13.91 & 14.70 & 14.30 \\
\hline SD & 2.0 & 2.19 & 2.28 & 1.76 & 1.84 & 1.91 \\
\hline Heritability & $0.22(0.02)$ & $0.23(0.03)$ & $0.22(0.02)$ & $0.14 \quad(0.01)$ & $0.09(0.01)$ & $0.15(0.01)$ \\
\hline Repeatability & $0.46(0.001)$ & $0.47(0.001)$ & $0.40(0.001)$ & $0.37(0.001)$ & $0.40(0.001)$ & $0.36(0.001)$ \\
\hline
\end{tabular}

\section{Disease Data from Denmark}

Many sires represented in the MUN data sets also had daughters and other relatives in Denmark. Denmark routinely publishes genetic evaluations for disease categories based on daughter disease data collected through the Danish recording program. Estimated breeding values for metabolic and digestive disease, reproductive disease, and foot and leg disease in first and second lactations in Denmark were obtained from the Danish Agricultural Advisory Center (Aarhus, Denmark). The Danish Health Traits Index was also available on each bull. This index indicates a bull's ability to sire daughters with increased resistance to diseases other than mastitis. The index includes reproductive, metabolic, and feet and leg diseases during the period of $10 \mathrm{~d}$ before calving to $100 \mathrm{~d}$ postcalving in first, second, and third lactations. Principles of Danish Cattle Breeding (2003) outlines procedures used in the calculation of breeding values and identifies diseases included in each disease category.

\section{Models for MUN}

All analyses, except for the calculation of correlations among EBV for Danish disease traits and US MUN, were conducted using ASREML (Gilmour et al., 2002). Preliminary analyses using random regression models on DIM allowing for heterogeneous residual variance resulted in heritabilities that were similar to those from the simpler model reported in this paper. Single-trait animal models with repeated records were used to estimate heritability and repeatability separately for MUN from first lactation, for MUN from second lactation, and for MUN from all lactations (1 through 5). Single-trait models used for heritability analysis included a fixed herd-test-day effect, a third-order polynomial for age at calving, a fourth-order polynomial for DIM, and random effects for animal, permanent environment, and error. Lactation number was included as an additional fixed effect in the model for MUN with all lactations combined. The single-trait model can be written as:

$$
\begin{gathered}
\mathrm{Y}_{\mathrm{ijklm}}=\mathrm{HTD}_{\mathrm{i}}+\mathrm{b}_{1 \mathrm{j}} \times \mathrm{AC}_{\mathrm{j}}+\mathrm{b}_{2 \mathrm{j}} \times\left(\mathrm{AC}_{\mathrm{j}}\right)^{2}+\mathrm{b}_{3 \mathrm{j}} \\
\times\left(\mathrm{AC}_{\mathrm{j}}\right)^{3}+\mathrm{b}_{1 \mathrm{k}} \times \mathrm{DIM}_{\mathrm{k}}+\mathrm{b}_{2 \mathrm{k}} \times\left(\mathrm{DIM}_{\mathrm{k}}\right)^{2} \\
+\mathrm{b}_{3 \mathrm{k}} \times\left(\mathrm{DIM}_{\mathrm{k}}\right)^{3}+\mathrm{b}_{4 \mathrm{k}} \times\left(\mathrm{DIM}_{\mathrm{k}}\right)^{4}+\mathrm{a}_{1}+\mathrm{pe}_{\mathrm{l}}+\mathrm{e}_{\mathrm{ijklm}},
\end{gathered}
$$

where $\mathrm{Y}_{\mathrm{ijklm}}$ represents a single MUN observation; $\mathrm{HTD}_{\mathrm{i}}$ is the herd-test-day for a single MUN observation; $b_{1 j}, b_{2 j}$, and $b_{3 j}$ are regression coefficients on the 3 orders for age at calving $\left(\mathrm{AC}_{\mathrm{j}}\right), \mathrm{b}_{1 \mathrm{k}}, \mathrm{b}_{2 \mathrm{k}}, \mathrm{b}_{3 \mathrm{k}}$, and $\mathrm{b}_{4 \mathrm{k}}$ are regression coefficients on the 4 orders for $\mathrm{DIM}_{\mathrm{k}}$; $\mathrm{a}_{1}$ represents the random animal effect; $\mathrm{pe}_{1}$ represents the permanent environmental effect; and $\mathrm{e}_{\mathrm{ijklm}}$ represents the random residual. Random animal effects were assumed correlated based on their genetic relationships calculated from all known pedigrees. Residual effects were assumed to be uncorrelated.

Table 2. Number of cows, means, standard deviations, and heritabilities (SE) for reproductive performance traits from wet chemistry data subset.

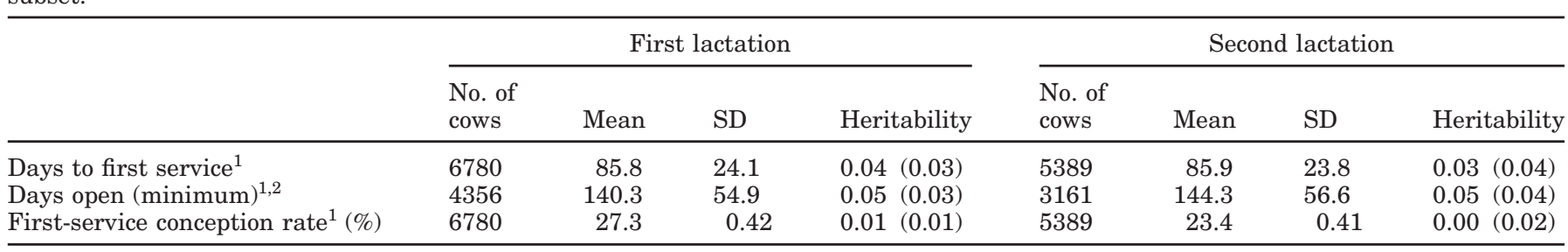

${ }^{1}$ Only records with first services within $\pm 30 \mathrm{~d}$ of a MUN measurement were considered.

${ }^{2}$ Days open calculated from records with producer-designated pregnancy status determined by palpation and reported to DHIA. 
Two-trait animal models were used to estimate genetic and phenotypic correlations among first- and second-lactation MUN values. These 2-trait models had the same effects as in the single-trait models but considered MUN in separate lactations as 2 different traits. Phenotypic correlations reported were from these 2trait models and were within herd-test-day.

Two-trait animal models were used to estimate genetic and phenotypic correlations between IR MUN and WC MUN. Correlations between IR MUN and WC MUN were estimated within first lactation and within second lactation. These models had the same effects as in the single trait models but considered IR MUN and WC MUN as 2 different traits. Phenotypic correlations from this analysis would not be meaningful because they would primarily reflect genetic covariance because individual cows did not have both IR and WC MUN records. Sample sizes are presented in Table 1.

Two-trait animal models were used to estimate correlations between reproductive performance measures and MUN (measured within $\pm 30 \mathrm{~d}$ of first service). These models were similar to the single-trait models and included polynomial terms up to third order for age at calving and polynomial terms up to fourth order for DIM and a fixed herd-year-season of calving effect. Herd-year-season of calving effects were used because reproductive performance traits were single measures and did not coincide with herd-test-days. Season of calving effects were defined as April through September and October through March. Random effects for animal, permanent environment, and error were included in the models. Phenotypic correlations between reproductive traits and MUN are from these 2-trait models and would be within herd-year-season of calving. Sample sizes are in Table 2.

\section{Correlations among MUN and Diseases}

Breeding values of sires with a minimum of 10 daughters for IR MUN and WC MUN were obtained from ASREML solution files (from the single-trait models described above) generated during the calculation of heritability for each trait. Breeding values for MUN were estimated separately for first and second lactations. Resulting sire breeding values were merged with EBV for diseases from Denmark. Data were edited to include only sires with a minimum reliability for MUN breeding values of $65 \%$ and a minimum reliability of $33 \%$ for EBV for Danish diseases.

Correlations between EBV for WC MUN and EBV for Danish diseases were calculated. Correlations were also calculated between EBV for IR MUN and EBV for Danish diseases. These correlations were then adjusted for reliability to yield approximate genetic correlations
(Calo et al., 1973). Approximate genetic correlations calculated by this method are free from environmental covariance because EBV were calculated from daughters in different environments. However, this method can result in genetic correlations outside the parameter space, especially when EBV have low reliabilities. In addition, calculation of standard errors is impossible.

Sire EBV for Danish diseases were also regressed on sire EBV for MUN to determine if there was any indication of a nonlinear genetic relationship between diseases and MUN. Linear regressions and quadratic regressions were both calculated. A significant quadratic regression would indicate that moderate EBV for MUN might be favorable or unfavorable when compared with low or high EBV for MUN.

\section{RESULTS AND DISCUSSION}

\section{Genetic and Phenotypic Parameters for MUN}

Average IR MUN for all lactations combined and average WC MUN for all lactations combined were 12.92 and $14.30 \mathrm{mg} / \mathrm{dL}$, respectively (Table 1). Jonker et al. (1998) reported an average of $13.51 \mathrm{mg} / \mathrm{dL}$. The Center for Animal Health and Productivity (2002) in Pennsylvania reported an average of $13.03 \mathrm{mg} / \mathrm{dL}$ based on more than 4 million records. Wood et al. (2003) reported an average IR MUN of $12.61 \mathrm{mg} / \mathrm{dL}$ for a data set that included approximately 36,000 records.

Heritabilities and repeatabilities for MUN in first lactation, in second lactation, and in all lactations are reported in Table 1. Estimated heritability for IR MUN ranged from 0.22 to 0.23 ( $\mathrm{SE}<0.03$ ), and was highest for second lactation. Heritability of WC MUN was 0.14 $(\mathrm{SE}=0.01)$ in first lactation, $0.09(\mathrm{SE}=0.01)$ in second lactation, and 0.15 ( $\mathrm{SE}=0.01)$ in all lactations combined. Genetic and phenotypic correlations between MUN measured in first and second lactations are in Table 3. Genetic correlations between first- and secondlactation MUN values were 0.99 for IR MUN and 0.98 for WC MUN. Phenotypic correlations between firstand second-lactation MUN values were 0.31 for IR MUN and 0.29 for WC MUN.

Wood et al. (2003) reported higher heritability estimates for IR MUN (0.44 in first lactation to 0.59 in second lactation) than those estimated in this study. Wood et al. (2003) used a random regression model to estimate heritabilities from approximately 6102 registered cows; data included 16,030 records in lactation 1 and 12,196 records in lactation 2 . The current IR MUN data set includes animals of both registered and nonregistered identity and totaled 38,355 and 25,519 records in first and second lactations, respectively. Inclusion of nonregistered animals would likely result in increased pedigree recording error. Further, Wood et al. (2003) 
Table 3. Genetic and phenotypic correlation estimates (SE) between MUN measured in first and second lactation and genetic correlation estimates (SE) between infrared (IR) MUN and wet chemistry (WC) MUN in first and second lactation.

\begin{tabular}{lllll}
\hline & $\begin{array}{l}\text { IR in first and } \\
\text { second lactation }\end{array}$ & $\begin{array}{l}\text { WC in first and } \\
\text { second lactation }\end{array}$ & $\begin{array}{l}\text { IR and WC } \\
\text { MUN in first } \\
\text { lactation }\end{array}$ & $\begin{array}{l}\text { IR and WC } \\
\text { MUN in second } \\
\text { lactation }\end{array}$ \\
\hline Genetic correlation & $0.99(0.01)$ & $0.98(0.01)$ & $0.38(0.08)$ & $0.23(0.08)$ \\
Phenotypic correlation & $0.31(0.01)$ & $0.29(0.01)$ & -1 & -1 \\
\hline
\end{tabular}

${ }^{1}$ Phenotypic correlation is not reported because it primarily reflects genetic covariance and little environmental covariance because individual cows did not have both IR and WC MUN records.

included only lactation records with at least 4 MUN observations. When our data were reanalyzed with this (Wood et al., 2003) imposed minimum of 4 MUN observations per lactation, resulting heritability estimates increased 2 to $3 \%$ with no change in repeatability. Additionally, Wood et al. (2003) included observations collected before October 1998 when MUN calibrations were standardized. No observations before calibration standardization were included in our analysis.

Heritability estimates were clearly higher for IR MUN than WC MUN, with IR MUN estimates ranging from 0.22 to 0.23 and WC MUN estimates varying from 0.09 to 0.15 . Genetic correlation between IR MUN and WC MUN in first lactation was $0.38(\mathrm{SE}=0.08)$ and between IR MUN and WC MUN in second lactation was $0.23(\mathrm{SE}=0.08$; Table 4). Apparently, IR MUN and WC MUN are genetically different traits.

Differences between the heritabilities of IR MUN and WC MUN may be explained in part by the laboratory procedures involved in the 2 methods. Complications associated with IR MUN include the knowledge that numerous other milk components, including butterfat, protein, and somatic cells may interfere with MUN estimations. Because the concentration of these other interfering components is known to vary widely from cow to cow, differing MUN estimates can result from separate samples even when the true urea concentration is the same (Godden et al., 2000). Wet chemistry methodology has routinely been accepted by the industry as a more accurate prediction of true MUN (National DHIA, 2003). Because of this advantage in accuracy, perhaps WC MUN is a better indicator of genetic differences in individual cows' abilities to metabolize protein than IR MUN values.

\section{Wet Chemistry MUN and Reproductive Performance}

Average days to first service was 85.8 in first lactation and 85.9 in second lactation (Table 2). Days open averaged 140.3 in first lactation and 144.3 in second lactation. First-service conception rates averaged $27.3 \%$ in services following first calving and $23.4 \%$ in services following second calving. Only those cows reported to be open or pregnant by palpation as reported to DHIA were used in calculation of first-service conception rate.

Estimated heritability of days to first service was 0.04 in first lactation and 0.03 in second lactation (Table 2). Heritability of DO was 0.05 for both parities. Standard errors for these 2 traits ranged from 0.03 to 0.04 . Estimates of heritability for first-service conception rate was $0.01(\mathrm{SE}=0.01)$ in first lactation and 0.0 $(\mathrm{SE}=0.02)$ in second lactation. Heritabilities for these reproductive traits in our study are similar to heritabilities found in other studies (Pryce et al., 2001; Berry et al., 2003).

Genetic and phenotypic correlations between WC MUN and reproductive performance measures are in Table 4 . With the exception of DO, genetic correlations between WC MUN and reproductive performance indicators were generally not different from zero, with estimates being less than or equal to the standard errors. Genetic correlations between WC MUN and DO were $0.21(\mathrm{SE}=0.17)$ in first lactation and were $0.41(0.27)$ in second lactation. Higher WC MUN concentrations may be genetically associated with increased DO. All phenotypic relationships between WC MUN and all measures of reproductive performance were close to zero. Two reports (Vallimont et al., 2003; Guo et al., 2004) indicated some relationship between MUN and

Table 4. Genetic and phenotypic correlations (SE) between wet chemistry MUN concentrations and reproductive performance measures in first and second lactations.

\begin{tabular}{|c|c|c|c|c|}
\hline & \multicolumn{2}{|c|}{ First-lactation MUN } & \multicolumn{2}{|c|}{ Second-lactation MUN } \\
\hline & Genetic & Phenotypic & Genetic & Phenotypic \\
\hline Days to first service & $-0.14(0.15)$ & $0.01(0.01)$ & $0.18(0.21)$ & $0.02(0.02)$ \\
\hline Days open & $0.21(0.17)$ & $0.01(0.02)$ & $0.41(0.27)$ & $0.04(0.02)$ \\
\hline First-service conception rate & $-0.06(0.24)$ & $0.01(0.01)$ & $0.01(0.52)$ & $-0.03(0.02)$ \\
\hline
\end{tabular}


Table 5. Correlations among EBV for disease traits in Denmark and EBV for MUN from the United States.

\begin{tabular}{lccccc}
\hline & \multicolumn{2}{c}{ First lactation } & & \multicolumn{2}{c}{ Second lactation } \\
\cline { 2 - 3 } \cline { 5 - 5 } Disease category & $\begin{array}{c}\text { Infrared } \\
(64 \text { sires })\end{array}$ & $\begin{array}{l}\text { Wet chemistry } \\
(63 \text { sires })\end{array}$ & & $\begin{array}{l}\text { Infrared } \\
(56 \text { sires })\end{array}$ & $\begin{array}{l}\text { Wet chemistry } \\
\text { (55 sires })\end{array}$ \\
\cline { 2 - 3 } & -0.04 & -0.11 & Correlations & among EBV & \\
Reproductive & -0.06 & 0.02 & $-0.25^{*}$ & -0.12 \\
Metabolic and digestive & -0.11 & 0.02 & -0.06 & 0.05 \\
Feet and leg & 0.17 & -0.04 & $-0.25^{*}$ & 0.10 \\
Health traits index & & Approximate genetic correlations ${ }^{1}$ & -0.02 \\
& -0.06 & -0.15 & $-0.35^{*}$ & -0.17 \\
Reproductive & -0.09 & 0.03 & -0.09 & 0.08 \\
Metabolic and digestive & -0.17 & 0.03 & $-0.38^{*}$ & 0.16 \\
Feet and leg & 0.23 & -0.05 & 0.10 & -0.03 \\
Health traits index & & &
\end{tabular}

${ }^{1}$ Correlations between EBV were adjusted for reliability of EBV to approximate genetic correlations.

$* P<0.07$.

reproductive traits on a within-herd basis. Guo et al. (2004) reported that cows with higher MUN had reduced conception rates. Vallimont et al. (2003) found that cows with a very high and very low MUN within the 2 -wk period before insemination had reduced conception rates. The genetic and phenotypic correlations estimated in this study would not, of course, be able to detect the nonlinear phenotypic relationship between MUN and conception rate as described by Vallimont et al. (2003). Moreover, in our study, MUN was measured within $\pm 30 \mathrm{~d}$ of first service. Restriction of MUN information to periods close to service dates might allow for detection of some type of genetic relationship between MUN and conception rates. However, this type of genetic analysis would be difficult to accomplish because of the limited number of recordings of MUN available within 2 wk of first service. Larger data sets in the future might allow for this type of genetic analysis. New approaches to lactation curve analysis might allow for estimation of the genetic relationship between MUN near service date and conception rate even when MUN near service date is unavailable.

\section{MUN and Cow Health}

Breeding value correlations and approximate genetic correlations among US MUN and various Danish disease traits are in Table 5. No correlations were significant. Correlations between MUN and metabolic and digestive diseases and between MUN and feet and leg diseases revealed no identifiable trends in either strength or direction of the relationship. Correlations between second-lactation IR MUN breeding values and second-lactation Danish breeding values for reproductive diseases and between second-lactation IR MUN breeding values and Danish breeding values for feet and leg diseases approached significance at $P<0.07$ and indicated a possible relationship of higher MUN concentrations associated with fewer reproductive and feet and leg diseases. Correlations between US MUN breeding values and the Danish Health Traits Index were also not significant. Results from the quadratic regression of EBV for Danish disease traits on EBV for MUN were all not significant. These results suggest that nonlinear (especially quadratic relationships that would provide indication of intermediate optimums for MUN EBV) relationships between EBV for MUN and Danish disease breeding values are not important.

\section{CONCLUSIONS}

Estimated heritability of WC MUN and IR MUN ranged from 0.09 to 0.15 and from 0.22 to 0.23 , respectively. These estimates were lower than previously reported estimates. Genetic and phenotypic correlations between MUN and several measures of reproductive performance were close to zero. Correlations between EBV for MUN from the United States and EBV for diseases from Denmark revealed no significant relationships. This study confirmed that heritable variation for MUN exists, but further research, especially with increased reproductive data, would be justified to further ascertain the possible inclusion of MUN in selection programs. Our results indicate a limited application of MUN for use in selection programs to improve either cow health or reproductive performance.

\section{ACKNOWLEDGMENTS}

The authors would like to thank the 3 anonymous reviewers who helped to dramatically improve the manuscript. 


\section{REFERENCES}

Berry, D. P., F. Buckley, P. Dillon, R. D. Evans, M. Rath, and R. F. Veerkamp. 2003. Genetic relationships among body condition score, body weight, milk yield, and fertility in dairy cows. J. Dairy Sci. 86:2193-2204.

Calo, L. L., R. E. McDowell, L. D. Van Vleck, and P. D. Miller. 1973. Genetic aspects of beef production among Holstein-Friesian pedigrees selected for milk production. J. Anim. Sci. 37:676-682.

Center for Animal Health and Productivity. 2002. Pennsylvania MUN values. Online. Available at: http://cahpwww.vet.upenn.edu/mun/ pa_mun_summ.html. Accessed Jan. 24, 2004.

Danish Cattle Federation. 2003. Principles of Danish Cattle Breeding. Online. Available at: http://www.1r.dk/kvaeg/diverse/principles.pdf. Accessed Jan. 20, 2004.

Ferguson, J. D. 2003. Milk Urea Nitrogen. Online. Available at: http:// cahpwww.vet.upenn.edu/mun/mun_info.html. Accessed Jan. 22, 2004.

Gilmour, A. R., B. R. Cullis, S. J. Welham, and R. Thompson. 2002 ASREML Reference Manual. 2nd ed. Online. Available at ftp:// ftp.res.bbsrc.ac.uk/pub/aar/asrref.pdf. Accessed July 9, 2003.

Godden, S. M., K. D. Lissemore, D. F. Kelton, K. E. Leslie, J. S. Walton, and J. H. Lumsden. 2000. Analytic validation of an infrared milk urea assay and effects of sample acquisition on milk urea results. J. Dairy Sci. 83:435-442.

Guo, K., E. Russek-Cohen, M. A. Varner, and R. A. Kohn. 2004. Effects of milk urea nitrogen and other factors on probability of conception of dairy cows. J. Dairy Sci. 87:1878-1885.

Jonker, J. S., R. A. Kohn, and R. A. Erdman. 1998. Using milk urea nitrogen to predict nitrogen excretion and utilization efficiency in lactating dairy cows. J. Dairy Sci. 81:2681-2692.

Lin, H. K., P. A. Oltenacu, L. D. Van Vleck, H. N. Erb, and R. D. Smith. 1989. Heritabilities of and genetic correlations among six health problems in Holstein cows. J. Dairy Sci. 72:180-186.

Melendez, P., A. Donovan, and J. Hernandez. 2000. Milk urea nitrogen and infertility in Florida Holstein cows. J. Dairy Sci. 83:459-463.

Moore, D. A., and G. Varga. 1996. BUN and MUN: Urea nitrogen testing in dairy cattle. Compend. Food Anim. 18:712-720.
National Dairy Herd Improvement Association. 2003. MUN quality control. Available at: http://www.dhia.org/muntable.htm. Accessed June 16, 2004.

Pryce, J. E., M. P. Coffey, and G. Simm. 2001. The relationship between body condition score and reproductive performance. J. Dairy Sci. 84:1508-1515.

Rajala-Schultz, P. J., W. J. A. Saville, G. S. Frazer, and T. E. Wittum. 2001. Association between milk urea nitrogen and fertility in Ohio dairy cows. J. Dairy Sci. 84:482-489.

Rogers, G. W., G. Banos, and U. Sander-Nielsen. 1999. Genetic correlations among protein yield, productive life, and type traits from the United States and diseases other than mastitis from Denmark and Sweden. J. Dairy Sci. 82:1331-1338.

Simianer, H., H. Solbu, and L. R. Schaeffer. 1991. Estimated genetic correlations between disease and yield traits in dairy cattle. J. Dairy Sci. 74:4358-4365.

USDA Animal Improvement Programs Laboratory. 2003. Genetic trend estimates. Online. Available at: http://aipl.arsusda.gov/dynamic/trend/current/trndx.html. Accessed Jan. 20, 2004.

Vallimont, J. E., G. W. Rogers, L. A. Holden, M. L. O’Connor, J. B. Cooper, C. D. Dechow, and J. S. Clay. 2003. Milk urea nitrogen and fertility: A population study using test-day records. J. Dairy Sci. 81(Suppl. 1):239. (Abstr.)

Van Dorp, T. E., J. C. M. Dekkers, S. W. Martin, and J. P. T. M. Noordhuizen. 1998. Genetic parameters of health disorders, and relationships with 305-day milk yield and conformation traits of registered Holstein cows. J. Dairy Sci. 81:2264-2270.

VanRaden, P. M., A. H. Sanders, M. E. Tooker, R. H. Miller, H. D. Norman, M. T. Kuhn, and G. R. Wiggans. 2004. Development of a national genetic evaluation for cow fertility. J. Dairy Sci. 87:2285-2292.

Veerkamp, R. F., E. P. C. Koenen, and G. De Jong. 2001. Genetic correlations among body condition score, yield, and fertility in first parity cows estimated by random regression models. J. Dairy Sci. 84:2327-2335.

Wood, G. M., P. J. Boettcher, J. Jamrozik, and D. F. Kelton. 2003. Estimation of genetic parameters for concentrations of milk urea nitrogen. J. Dairy Sci. 86:2462-2469. 